Original Research Article

\title{
The effect of acetylation phenotype on the dynamic changes of indices of calcium metabolism and iron levels in liver detoxification on the background of experimental hypothyroidism
}

\author{
Saidamir Saidov, Asilbek Ahmadjonuv*, Anvar Mavlonov
}

Department of Pharmacology, Tashkent Pharmaceutical Institute, Tashkent 100147, Uzbekistan

Received: 10 February 2017

Revised: 19 February 2017

Accepted: 24 February 2017

*Correspondence to:

Asilbek Ahmadjonuv,

Email: author.uzb@mail.ru

Copyright: (C) the author(s), publisher and licensee Medip Academy. This is an openaccess article distributed under the terms of the Creative Commons Attribution NonCommercial License, which permits unrestricted noncommercial use, distribution, and reproduction in any medium, provided the original work is properly cited.

\begin{abstract}
Background: Some studies of the characteristics of the calcium-phosphorus metabolism changes in experimental hypothyroidism given the phenotype of acetylation will allow to more effectively diagnose, predict the course and to carry out prevention and treatment of hypothyroidism and the accompanying pathological changes.

The aim is to trace the dynamics of phosphorus-calcium metabolism and the level of serum iron in experimental hypothyroidism and to determine the severity of it changes depending on the type of acetylation.

Methods: In experiments were used rats weighing 180-220g, who were divided into 2 main groups depending on the type of acetylation on $\alpha$ - slow and $\beta$ - fast metabolizer (acetylators). Each group was modelled experimental hypothyroidism by the introduction of mercazolil at a dose of $5 \mathrm{mg}$, for 14 days. Each group was divided into 5 subgroups depending on the time of the study. Group of $\alpha$-slow metabolizers (acetylators) were divided into the following subgroups: I $\alpha$ - intact II $\alpha$ - at the $4^{\text {th }}$ hour of the study, III $\alpha$ - on the $1^{\text {st }}$ week of the study, IV $\alpha$ - 2-week studies, V $\alpha$ - on the $3^{\text {rd }}$ week of the study.

Results: In the study of the calcium concentration at the $4^{\text {th }}$ hour of the study in subgroups with $\alpha$ - and $\beta$ - acetylation phenotypes were observed the decrease by $12.0 \%$ and $10.5 \%$ respectively, and its level in the II $\beta$ - subgroup was $5.3 \%$ lower than the II $\alpha$ - subgroup. The concentration of calcium ions in $\mathrm{V} \alpha$ subgroup was lower than in the I $\alpha$ sub-group was $12.0 \%$, and the level of calcium in the blood serum of animals V $\beta$ was lower compared to I $\beta$ II $\beta$ III $\beta$ Iv $\beta-90.9 \%$, $72.7 \%, 80.0 \%, 80.9 \%$ respectively. Also relatively, $\mathrm{V} \alpha \mathrm{V} \beta$ subgroups in the subgroup calcium concentration were lower at 81.8 percent.

Conclusions: Belonging to a particular phenotype of acetylation affects the degree of severity of the changes of indices of calcium-phosphorus metabolism and serum iron in experimental hypothyroidism, the most significant differences between the values of their indicators were detected early and deadlines of the study.
\end{abstract}

Keywords: Acetylation, Calcium-phosphorus metabolism, Hypothyroidism, Iron, Liver detoxification

\section{INTRODUCTION}

According to various epidemiological studies, the prevalence of hypothyroidism is a quite significant level. So according to some authors clinically evident hypothyroidism in the General population is $2 \%{ }^{1}$ According to some authors, the incidence of hypothyroidism is often accompanied by functional disorders of the kidneys, which in turn can lead to an electrolyte imbalance in the blood serum, which is known, according to various studies, is very sensitive to neuroendocrine changes. ${ }^{2}$

According to the literature, the rate of metabolic processes in the body determines the speed of development of the many biochemical changes in the blood, leading to the development of various pathological processes, including development-related functional disorders of the thyroid gland. ${ }^{3}$ As is known, the genetic polymorphism of the gene acetyl-transferase is one of the 
key points that influence the rate of biotransformation enzymes. ${ }^{4}$

A deeper study of the characteristics of the changes of calcium-phosphorus metabolism in experimental hypothyroidism given the phenotype of acetylation will allow to more effectively diagnose, predict the course and to carry out prevention and treatment of hypothyroidism and the accompanying pathological changes. ${ }^{2,5}$

The aim of this work is to trace the dynamics of phosphorus-calcium metabolism and the level of serum iron in experimental hypothyroidism and to determine the severity of it changes depending on the type of acetylation.

\section{METHODS}

In experiments were used rats weighing 180-220g, who were divided into 2 main groups depending on the type of acetylation on $\alpha-$ slow and $\beta$ - fast metabolizer (acetylators). Each group was modeled experimental hypothyroidism by the introduction of mercazolil at a dose of $5 \mathrm{mg}$, for 14 days. ${ }^{6}$ Each group, in turn, was divided into 5 subgroups depending on the time of the study. Therefore, group of $\alpha$-slow metabolizers (acetylators) were divided into the following subgroups: I $\alpha$ - intact II $\alpha$ - at the $4^{\text {th }}$ hour of the study, III $\alpha$ - on the 1 st week of the study, IV $\alpha$ - 2-week studies, V $\alpha$ - on the 3rd week of the study. Accordingly, the group of $\beta$ metabolizer fast (acetylators) consisted of the following subgroups: I $\beta$ - intact II $\beta$ - at the 4 th hour of the study III $\beta$ - 1-week studies, IV $\beta$ - 2-week studies, V $\beta$ - to 3-week study. Dynamics of indicators of thyroid hormones, reflecting the development of the pathological process, were evaluated in these subgroups separately, depending on the speed and type of acetylation. The results of this comparison are reflected in Table 2. Moreover, it was made combining data of two similar subgroups of the corresponding period with a different rate of acetylation, statistically processed and the results were compared with those of other gathered subgroups of different study periods, as shown in Table 1 . This table describes the changes levels of thyroid hormones occurring in I $\alpha \beta$, II $\alpha \beta$, III $\alpha \beta$, IV $\alpha \beta$ and IV $\alpha \beta$ groups.

We studied the levels of calcium, phosphorus, and iron in the blood serum of experimental animals. The studied parameters were studied as in combined groups, which included $\alpha$ and $\beta$ subgroups (with a phenotype of "slow" and "fast" acetylation of metabolic system of the body, respectively), and these subgroups separately, and also tested the significance of differences between them.

The acetylation phenotype was determined by the standard technique. ${ }^{6}$ The concentration of biochemical parameters in serum was determined by semiautomatic biochemical analyser "BA88" (Mindray, China), with test system "Human" (Germany). ${ }^{5}$ Statistical processing was performed using the programs Excel and Biostat.

\section{RESULTS}

At various stages of experimental modeling of hypothyroidism observed changes in the studied biochemical indicators, including the functional activity of the organs of the excretory system, in particular, in the composition of electrolytes and essential in the balance of minerals.

The level of calcium ions significant changes were observed only at the 4th hour of observation, which was lower by $11.8 \%$ (Table 1 ).

\section{Table 1: Changes of some indicators of phosphorus- calcium metabolism and the level of serum iron during experimental hypothyroidism $(\mathrm{M} \pm \mathrm{m})$.}

\begin{tabular}{|llll|}
\hline $\begin{array}{l}\text { Study } \\
\text { groups }\end{array}$ & $\begin{array}{l}\text { Calcium } \\
(\mathrm{mmol} / \mathrm{l})\end{array}$ & $\begin{array}{l}\text { Phosphorus } \\
(\mathrm{mmol} / \mathrm{l})\end{array}$ & $\begin{array}{l}\text { Ferrum } \\
(\mathrm{mkmol} / \mathrm{l})\end{array}$ \\
\hline $\begin{array}{l}\mathrm{I}_{\alpha \beta} \text { intact } \\
\text { group }\end{array}$ & $2.18 \pm 0.09$ & $0.96 \pm 0.07$ & $13.1 \pm 0.5$ \\
\hline $\begin{array}{l}\mathrm{II}_{\alpha \beta} \text { group } \\
(4 \text { hours })\end{array}$ & $1.95 \pm 0.04^{*}$ & $0.87 \pm 0.04$ & $12.88 \pm 0.33$ \\
\hline $\begin{array}{l}\mathrm{II}_{\alpha \beta} \text { group } \\
\left(1^{\mathrm{st}} \text { week }\right)\end{array}$ & $2.01 \pm 0.03$ & $0.89 \pm 0.01$ & $12.63 \pm 0.24$ \\
\hline $\begin{array}{l}\mathrm{IV}_{\alpha \beta} \text { group } \\
\left(2^{\text {nd }} \text { week }\right)\end{array}$ & $2.00 \pm 0.01$ & $0.89 \pm 0.01$ & $13.10 \pm 0.25$ \\
\hline $\begin{array}{l}\mathrm{V}_{\alpha \beta} \text { group } \\
\left(3^{\text {rd }} \text { week }\right)\end{array}$ & $1.55 \pm 0.46$ & $0.85 \pm 0.06$ & $13.50 \pm 0.15 \#$ \\
\hline
\end{tabular}

* - significant difference $(\mathrm{P}<0.05)$ when comparing results with data in intact; $\wedge$ - same when comparing results with the data in the $1^{\text {st }}$ group; \# - same when comparing results with the date in the $2^{\text {nd }}$ group; and - same when comparing results with the data in the $3^{\text {rd }}$ group; $\$$ - same when comparing results with the data in the same group with the subgroup of slow acetylators.

In the concentration of phosphorus in the modeling of experimental hypothyroidism significant changes are detected. In the hardware level of a significant change in only 3 weeks of observations on the 1 -week experiment of $6.9 \%$.

When studying changes in concentrations of studied parameters in the group with different phenotypes of acetylation observed changes at different stages of the study.

In the study of the calcium concentration at the 4th hour of the study in subgroups with $\alpha$ - and $\beta$ - acetylation phenotypes were observed the decrease by $12.0 \%$ and $10.5 \%$ respectively, and its level in the II $\beta$ - subgroup was $5.3 \%$ lower than the II $\alpha$ - subgroup.

1- week change relative to the values of the original indicators ( $\mathrm{I} \alpha$ and I $\beta$ subgroups) was not observed, but in comparison with the values in the II $\beta$ - III $\beta$ in the subgroup has an increased concentration of calcium ions is $4.2 \%$, whereas the $\alpha$ and $\beta$ subgroups of the 1 st week, significant changes were noted. 
Table 2: Changes in the indices of phosphorus-calcium metabolism and the level of serum iron in rats at modeling of hypothyroidism in subgroups with $\alpha$ - and $\beta$-acetylation phenotypes $(M \pm m)$.

\begin{tabular}{|c|c|c|c|c|}
\hline \multicolumn{2}{|l|}{ Study groups } & Calcium (mmol/l) & Phosphorus (mmol/l) & Ferrum (mkmol/l) \\
\hline \multirow{2}{*}{$\mathrm{I}_{\alpha \beta}$ intact group } & $\mathrm{I}_{\alpha}$ subgroup & $2.24 \pm 0.1$ & $1.08 \pm 0.1$ & $14.70 \pm 0.8$ \\
\hline & $I_{\beta}$ subgroup & $2.10 \pm 0.08$ & $0.90 \pm 0.06$ & $12.90 \pm 0.5$ \\
\hline \multirow{2}{*}{$\begin{array}{l}\text { II }_{\alpha \beta} \text { group } \\
\text { (4 hour) }\end{array}$} & $\mathrm{II}_{\alpha}$ subgroup & $2.00 \pm 0.01 *$ & $0.90 \pm 0.01$ & $12.77 \pm 0.31^{*}$ \\
\hline & $\mathrm{II}_{\beta}$ subgroup & $1.90 \pm 0.01 * \$$ & $0.84 \pm 0.02 \$$ & $13.00 \pm 0.45$ \\
\hline \multirow{2}{*}{$\begin{array}{l}\mathrm{III}_{\alpha \beta} \text { group } \\
\left(1^{\text {st }} \text { week }\right)\end{array}$} & $\mathrm{III}_{\alpha}$ subgroup & $2.03 \pm 0.04$ & $0.90 \pm 0.01$ & $12.83 \pm 0.29$ \\
\hline & $\mathrm{III}_{\alpha}$ subgroup & $1,98 \pm 0.01^{\wedge}$ & $0.88 \pm 0.01$ & $12.43 \pm 0.22$ \\
\hline \multirow{2}{*}{$\begin{array}{l}\text { IV }_{\alpha \beta} \text { group } \\
\text { (2 }{ }^{\text {nd }} \text { week) }\end{array}$} & $\mathrm{IV}_{\alpha}$ subgroup & $2.00 \pm 0.01 *$ & $0.90 \pm 0.01$ & $13.33 \pm 0.31$ \\
\hline & $I_{\beta}$ subgroup & $1.99 \pm 0.01^{\wedge}$ & $0.89 \pm 0.01^{\wedge}$ & $12.87 \pm 0.21$ \\
\hline \multirow{2}{*}{$\begin{array}{l}V_{\alpha \beta} \text { group } \\
\left(3^{\text {rd }} \text { week }\right)\end{array}$} & $\mathrm{V}_{\alpha}$ subgroup & $2.00 \pm 0.01 *$ & $0.90 \pm 0.01$ & $13.67 \pm 0.15^{\wedge} \#$ \\
\hline & $\mathrm{V}_{\beta}$ subgroup & $1.10 \pm 0.05^{* \wedge} \#$ and $\$$ & $0.80 \pm 0.01 \#$ and $\$$ & $13.33 \pm 0.15$ \\
\hline
\end{tabular}

* - significant difference $(\mathrm{P}=0.05)$ when comparing results with data in intact., ${ }^{\wedge}$ - same when comparing results with the data in the $1^{\text {st }}$ group., \# - same when comparing results with the data in $2^{\text {nd }}$ group., - same when comparing results with the data in the $3^{\text {rd }}$ group., $\$$ same when comparing results with the data in the same group with subgroup low resistant.

In IV $\alpha$ subgroup relative to the subgroup I $\alpha$ calcium concentration was lower at $12.0 \%$, as compared to II $\alpha$, and III $\alpha$ subgroups changes were not observed. In IV $\beta$ subgroup calcium concentration was higher relative to its values in the subgroup II $\beta 4.7 \%$, at the same time; significant changes regarding the subgroups with $\beta$ acetylation phenotype at other earlier stages of the study were noted.

The concentration of calcium ions in $\mathrm{V} \alpha$ subgroup was lower than in the I $\alpha$ sub-group was $12.0 \%$, and the level of calcium in the blood serum of animals $\mathrm{V} \beta$ was lower compared to I $\beta$ II $\beta$ III $\beta$ IV $\beta-90.9 \%, 72.7 \%, 80.0 \%$, $80.9 \%$ respectively. Also relatively, $\mathrm{V} \alpha \mathrm{V} \beta$ subgroups in the subgroup calcium concentration were lower at 81.8 percent.

In the study of the phosphorus concentration on the 4hour study, significant changes were not observed, but the differences between the subgroups with different acetylation phenotype were more pronounced. Therefore, II $\beta$ subgroup of the concentration of phosphorus was higher than the II $\alpha$ subgroup of $7.1 \%$. At the same time on the 1 week of the study, significant changes relative to earlier periods and baseline was not observed, as between III $\alpha$ and III $\beta$ subgroups.

On the $2^{\text {nd }}$ week of the study, the concentration of phosphorus was higher IV $\beta$ subgroup than in the subgroup II $\beta 5.6 \%$. In the subgroup with $\alpha$-acetylation phenotype, significant changes in the concentration of phosphorus were not observed even in comparison with values of similar subgroups in the earlier stages of the study, neither relative to the original data.

On the $3^{\text {rd }}$ week in $V \beta$ subgroup in contrast to the $\mathrm{V} \alpha$ subgroup, the observed changes in the concentration of phosphorus, compared III $\alpha$ subgroup was lower by
$10.0 \%$, compared to its value in the subgroup IV $\beta$ $11.3 \%$, and with respect to V $\alpha$ subgroup - by $12.5 \%$.

The concentration of iron ions at the 4th hour of the study in the subgroup with a - phenotype decreased relative to its value in the subgroup with intact animals with phenotype $15.1 \%$. In the subgroup with $\alpha$-acetylation phenotype in this period significant changes in the concentration of serum iron were not observed, as any significant changes regardless of the phenotype of acetylation on the $1^{\text {st }}$ and $2^{\text {nd }}$ week.

In the subgroup $\mathrm{V} \alpha$, the concentration of serum iron was increased compared to its value in the subgroup II $\alpha$ by $7.0 \%$, as compared with III $\alpha$ subgroup by $2.6 \%$.

Therefore, the changes of calcium concentration in experimental hypothyroidism were noted in subgroups with $\alpha$ - and $\beta$-acetylation phenotypes, but the most pronounced of them there was observed in the case of a $\beta$-acetylation phenotype. Especially pronounced changes in the concentration of calcium were noted at the 4th hour and the 3rd week of experimental hypothyroidism.

Phosphorus concentration did not change so pronounced as the level of calcium in experimental hypothyroidism, however, however, changes that are more significant were observed with $\beta$ - acetylation phenotype, and the most significant of them were also observed in the extreme period of the study.

In contrast to the above patterns, the concentration of serum iron was changed more significantly in subgroups with $\alpha$-acetylation phenotype. The most pronounced changes were observed at the $4^{\text {th }}$ hour and the $3^{\text {rd }}$ week of the experiment.

Changes of the blood biochemical indicators, such as urea and creatinine, which characterize intensity of 
catabolic processes, were observed at various stages of the modeled experimental hypothyroidism.

In this way, the level of urea in the $1^{\text {st }}$ week of study was significantly higher than that indicator of animals from intact group, which was higher by $48.2 \%$, and with respect to the in the 4 hour experimental group of modeled thyroid pathology by $43.4 \%$ (Table 1 ). The level of this indicator in the 2 nd week with respect to indicators of animals from intact group and animals from 4 hour group was higher by $48.7 \%$ and $43.9 \%$, respectively; the analogous difference in the $3 \mathrm{rd}$ week was $64.1 \%$ and $58.8 \%$.

Significantly high levels of creatinine were observed only in the 3rd week of experimental hypothyroidism, relative to the indices of animals of intact group, $4^{\text {th }}$ hour, $1^{\text {st }}$ and $2^{\text {nd }}$ weeks, were respectively, $23.6 \%, 33.9 \%, 22.1$ and $23.8 \%$. It is clear from the provided data that there is a more pronounced difference in the $3^{\text {rd }}$ week of experiment, with respect to the parameters of 4 th hour, $1^{\text {st }}, 2^{\text {nd }}$ weeks of study, indicating lower serum creatinine values at an early period of experimental hypothyroidism.

As a result of the analysis of the results obtained in groups, separated according to the acetylation phenotype, statistically significant differences were found in the studied parameters (Table 2).

\section{Table 3: Changes in individual blood biochemical parameters of rats in modelled hypothyroidism $(\mathrm{M} \pm \mathrm{m})$.}

\begin{tabular}{|lll|}
\hline Studied groups & $\begin{array}{l}\text { Urea } \\
(\mathrm{mmol} / \mathrm{L})\end{array}$ & $\begin{array}{l}\text { Creatinine } \\
(\mathrm{mcm}) / \mathrm{L})\end{array}$ \\
\hline $\begin{array}{l}\text { I } \alpha \beta \text { groups of } \\
\text { intact animals }\end{array}$ & $3.90 \pm 0.75$ & $57.20 \pm 2.6$ \\
\hline $\begin{array}{l}\text { II } \alpha \beta \text { groups }\left(4^{\text {th }}\right. \\
\text { hour })\end{array}$ & $4.03 \pm 0.87$ & $52.78 \pm 2.5$ \\
\hline $\begin{array}{l}\text { III } \alpha \beta \text { groups }\left(1^{\text {st }}\right. \\
\text { week })\end{array}$ & $5.78 \pm 0.19 * \wedge$ & $57.90 \pm 1.08$ \\
\hline $\begin{array}{l}\text { IV } \alpha \beta \text { groups }\left(2^{\text {nd }}\right. \\
\text { week })\end{array}$ & $5.80 \pm 0.12^{* \wedge}$ & $57.08 \pm 0.90$ \\
\hline $\begin{array}{l}\text { V } \alpha \beta \text { groups }\left(3^{\text {rd }}\right. \\
\text { week) }\end{array}$ & $6.40 \pm 0.30 * \wedge$ & $\begin{array}{l}70.68 \pm 1.80 * \wedge \# \\
\text { and }\end{array}$ \\
\hline
\end{tabular}

* - significant difference $(\mathrm{P}<0.05)$ when comparing results with those in the group of intact animals; $\wedge$ - same in comparing results with those in group 1; \# - same in comparing results with those in group 2; and - same when comparing results with those in group 3; $\$$ - same in comparing results with data in the same group to a subgroup of slow acetylators.

In this way, the level of urea in animals who were $\beta$ - fast metabolizers (acetylators) at 4 hour of the study was higher by $47.4 \%$ relative to the parameters of intact animals with a similar phenotype, and on the $1^{\text {st }}, 2^{\text {nd }}$ and $3^{\text {rd }}$ weeks, this difference was $52.3 \%, 48.9 \%$ and $76.0 \%$. In the subgroup with $\alpha$ - "slow" metabolism phenotype (acetylation), a statistically significant increase in the concentration of urea compared with intact animals was observed only on the $3^{\text {rd }}$ week of the study and was $40.0 \%$.

Table 4: Changes in individual blood biochemical
parameters rat modelling of the experimental hypothyroidism subgroup with $\alpha$ - and $\beta$ - acetylating phenotype $(\mathrm{M} \pm \mathrm{m})$.

\begin{tabular}{|c|c|c|c|}
\hline $\begin{array}{l}\text { Groups, } \\
\text { (term of } \\
\text { study) }\end{array}$ & Subgroups & $\begin{array}{l}\text { Urea } \\
(\mathrm{mmol} / \mathrm{L})\end{array}$ & $\begin{array}{l}\text { Creatinine } \\
\text { (mcmol/L) }\end{array}$ \\
\hline \multirow{2}{*}{$\begin{array}{l}\text { I } \alpha \beta, \\
\text { (intact) }\end{array}$} & $\mathrm{I} \alpha$ & $3.8 \pm 0.8$ & $56.4 \pm 1.8$ \\
\hline & $\mathrm{I} \beta$ & $4.05 \pm 0.65$ & $58.1 \pm 2.1$ \\
\hline \multirow{2}{*}{$\begin{array}{l}\text { II } \alpha \beta,\left(4^{\text {th }}\right. \\
\text { hour })\end{array}$} & II $\alpha$ & $2.10 \pm 0.07$ & $35.07 \pm 2.47 *$ \\
\hline & $\mathrm{II} \beta$ & $5.97 \pm 0.05 * \$$ & $70.50 \pm 0.09 * \$$ \\
\hline \multirow{2}{*}{$\begin{array}{l}\text { III } \alpha \beta, \\
\left(1^{\text {st }}\right. \\
\text { week })\end{array}$} & III $\alpha$ & $5.40 \pm 0.12^{\wedge}$ & $50.97 \pm 0.14^{* \wedge}$ \\
\hline & III $\beta$ & $6.17 \pm 0.09 * \$$ & $64.83 \pm 0.94 * \wedge \$$ \\
\hline \multirow{2}{*}{$\begin{array}{l}\text { IV } \alpha \beta, \\
\left(2^{\text {nd }}\right. \\
\text { week })\end{array}$} & $\mathrm{IV} \alpha$ & $5.57 \pm 0.02^{\wedge}$ & $51.33 \pm 0.16^{* \wedge}$ \\
\hline & $\operatorname{IV} \beta$ & $6.03 \pm 0.10 * \$$ & $62.83 \pm 0.70^{\wedge} \$$ \\
\hline \multirow{2}{*}{$\begin{array}{l}\mathrm{V} \alpha \beta, \\
\left(3^{\text {rd }}\right. \\
\text { week })\end{array}$} & $\mathrm{V} \alpha$ & $5.67 \pm 0.05^{* \wedge}$ & $\begin{array}{l}56.33 \pm 1.04^{\wedge} \# \\
\text { and }\end{array}$ \\
\hline & $\mathrm{V} \beta$ & $\begin{array}{l}7.13 \pm 0.06^{* \wedge} \# \\
\text { and } \$\end{array}$ & $\begin{array}{l}85.03 \pm 0.48^{* \wedge \#} \\
\text { and } \$\end{array}$ \\
\hline
\end{tabular}

* - significant difference $(\mathrm{P}<0.05)$ when comparing results with those in the group of intact animals; ${ }^{\wedge}$ - same when comparing results with those in group 1; \# - same when comparing results with those in group 2; and - same when comparing the results with those in group $3 ; \$$ - same when comparing results with the data in the same group with $\alpha$-subgroup of unstable metabolizers.

Compared to the $4^{\text {th }}$ hour studies, in subgroups with $\beta$ "fast" phenotype of (acetylation) metabolism, a statistically significant increase in the level of urea was observed in the $3^{\text {rd }}$ week of experiment and comprised $19.4 \%$. In III $\alpha, \mathrm{IV} \alpha, \mathrm{V} \alpha$ subgroups, relatively to II $\alpha$ subgroup, the urea concentration was higher by $2.6,2.7$ and 2.7 times, respectively. In the subgroup with $\beta$ acetylation phenotype, higher rates were observed at ultimate terms ( $3^{\text {rd }}$ week) of experiment compared to the 1 st and 2nd weeks, which were $15.6 \%$ and $18.2 \%$ higher.

Statistically significant differences in the levels of urea among subgroups with different phenotypes of acetylation, except intact animals, were observed in almost all terms - on the 4th hour, $1^{\text {st }}, 2^{\text {nd }}$ and $3^{\text {rd }}$ weeks of study and their values were higher by $184.3 \%, 14.3 \%$, $8.3 \%$ and $25.7 \%$ respectively, in subgroups with phenotype of $\beta$ - acetylation compared to phenotype of $\alpha$ acetylation. Surveying the results of the study, it should be noted that there were insignificant of differences between subgroups with different rates of metabolism in the development of thyroid pathology and only a slight increase in these differences at ultimate term.

The obtained results demonstrate that the concentration of urea at $4^{\text {th }}$ hour term of study decreased insignificantly in subgroups with $\alpha$-acetylation phenotype, whereas a 
statistically significant increase in this parameter was present in subgroups of animals with $\beta$-phenotype.

In all subsequent terms of studies, there were higher levels of urea relatively to the $4^{\text {th }}$ hour with subgroups of $\alpha$-phenotype. At the same time, there were higher levels of urea relatively to intact animals in subgroup with $\beta$ phenotype, compared to the concentration of it in $\alpha$ subgroups.

However, the indicator was not noted to change in dynamics, except for the ultimate term, where differences relatively to earlier terms were more pronounced compared to the differences in the values of urea in subgroups with $\alpha$-acetylation phenotype. In general, dynamics of the urea level may suggest about more active changes of this indicator in the subgroup of $\beta$ - "fast" metabolizers, compared to metabolizers with $\alpha$ - "slow" phenotype.

As is known, the basic way of neutralization of highlytoxic ammonia in the liver, which results from degradation of amino acids, is the formation of urea that is excreted with urine as a final product of protein metabolism in the body. The observed changes in the urea level may imply the extent of influence of experimental hypothyroidism, as on the intensity of catabolic processes as well as on the efficiency of the detoxifying ability of liver, associated with phenotype of acetylation.

As concerning the level of creatinine, subgroup with $\alpha$ acetylation phenotype had lower by $60.8 \%$ values at 4 hour term, and in the subgroup with $\beta$ - "fast" phenotype of metabolism was by $21.3 \%$ higher, compared to indicators of intact animals.

In comparison with indicators of intact animals in subgroups with $\alpha$ - and $\beta$-phenotype creatinine concentration at the $1 \mathrm{st}$ week of study was by $10.7 \%$ lower and $11.6 \%$ higher, respectively. On the $2^{\text {nd }}$ week of experiment, with respect to indicators of intact animals, statistically significant differences occurred in the subgroup with $\alpha$-phenotype, where serum creatinine was 9.9\% lower and at $3^{\text {rd }}$ week in animals with $\beta$-phenotype where this parameter was greater by $46.4 \%$.

Comparing indicators within both "fast" and "slow" subgroups the results of creatinine concentration at 4hour period were $45.3 \%$ higher and $8.7 \%$ lower, while in the $2^{\text {nd }}$ and $3^{\text {rd }}$ weeks of experimental pathology, relative to the same period of comparison, $46.4 \%$ higher and $12.2 \%$ lower, respectively, and by $60.6 \%$ and $82.3 \%$ higher. Compared with the 1 st week results, there were no significant changes observed in IV $\alpha$ and $\operatorname{IV} \beta$ subgroups, and in $\mathrm{V} \alpha$ and $\mathrm{V} \beta$ subgroups creatinine level was higher by $10.5 \%$ and $31.2 \%$, respectively. On the $3^{\text {rd }}$ week, the levels of creatinine relatively to those in the $2^{\text {nd }}$ week of experiment were by $9.7 \%$ higher in the subgroups with $\alpha$-acetylation phenotype, and by $35.3 \%$ higher in the subgroup with $\beta$ - "fast" metabolism.

Analyzing concentration of creatinine in subgroups with $\beta$-phenotype with respect to indicators of $\alpha$ - "slow" metabolizers, significant changes were observed at 4 hour term, where their concentration was twofold higher. On the $1^{\text {st }}, 2^{\text {nd }}$ and $3^{\text {rd }}$ weeks this difference comprised $27.2 \%, 22.4 \%$ and $50.9 \%$. As can be noted from the above given results, the biggest difference between the two groups with different metabolic rates was observed in the early and late terms of experimental hypothyroidism.

In the study of changes of creatinine concentration at the earliest term of experiment ( 4 hour), in comparing the level of these parameters with intact animals, it should be noted decrease of their values was observed in the subgroups with $\alpha$ - "slow" phenotype, and, this trend preserved almost at all study periods, except for the ultimate, where statistically significant differences were not detected. By contrast, creatinine concentration in groups with $\beta$ - acetylation phenotype increased at all stages of experimental hypothyroidism. The results of changing concentrations of creatinine indicate that phenotype of acetylation has a significant impact on its level in the blood serum in experimental hypothyroidism.

\section{DISCUSSION}

As is known, a significant portion of nitrogen, produced by the process of degradation of amino acids and formed from creatine and creatine phosphate, is excreted from body in the form of creatinine. Thus, creatinine, along with urea, is an important indicator of protein degradation. ${ }^{6}$

Significant changes in the direction of creatinine concentration between subgroups with different acetylation phenotype suggest about differences in the mechanisms of utilization of products of protein degradation, which animals have depending on the type and rate of their metabolism in conditions of experimental hypothyroidism. It is known that normally, from total amount of nitrogen excreted with urine fraction of that in urea accounts for about $85 \%$, in creatinine about $5 \%$, the remaining percentage is distributed among ammonium salts, uric acid and other compounds. ${ }^{7,8}$ The obtained results suggest not only changes in the concentrations of urea and creatinine in general, but also their relationship to each other. ${ }^{9}$

In support of what was said, ratios of urea to creatinine in subgroups with $\alpha$-acetylation phenotype in intact animals, at 4-hour, 1-week, 2-week and 3-week terms of experimental hypothyroidism were 67.4, 58.9, 105.9, 108.5 and $100.7 \%$, respectively. An analogous correlation between urea and creatinine levels in the groups with $\beta$ acetylation phenotype at the same terms of study gave following ratios: 69.7, 84.7, 95.2, 96.0 and 100.7\%, respectively. As seen from the above values, if in $\alpha$ - 
subgroups this ratio drops sharply at early terms, then by the 1 st week it sharply increases, growing to $2^{\text {nd }}$ week and slightly decreasing at ultimate term. In groups with $\beta$ phenotype, by contrast, even though all stages increase of values of urea to creatinine was noted. In general, comparable in intact with different phenotype animals values of the ratio of urea to creatinine become significantly different at 4 hour term, which with the development of experimental hypothyroidism slightly level out, disappearing toward the ultimate term of experiment. $^{10}$

The results obtained in studying individual parameters, which characterize the activity of the processes of protein degradation and liver detoxification in experimental hypothyroidism; demonstrate a statistically significant difference in the dynamics of changes in the values of these parameters between the subgroups with $\alpha$ - and $\beta$ acetylation phenotypes.

The most pronounced differences of values among subgroups are shown to be in the group with $\beta$ - "fast" phenotype of metabolism, unlike those found in a group with $\alpha$-phenotype of metabolic activity. It should also be noted that the most significant differences of the studied parameters as comparing various periods of study, as well as between subgroups of same terms, appear in the later stages of the simulated experimental hypothyroidism. ${ }^{11}$

\section{CONCLUSION}

- Belonging to a particular phenotype of acetylation affects the degree of severity of the changes of indices of calcium-phosphorus metabolism and serum iron in experimental hypothyroidism, the most significant differences between the values of their indicators were detected early and deadlines of the study.

- $\quad$ The presence of $\beta$-acetylation phenotype determines a greater severity of the changes in the concentration of calcium and phosphorus in experimental hypothyroidism than with $\alpha$-phenotype, with the greatest severity is manifested in the extreme periods of the study.

- The presence of $\alpha$-acetylation phenotype determines a greater severity of the changes in the concentration of serum iron in experimental hypothyroidism than with $\beta$-phenotype, which is manifested mainly on the deadlines of the study.

- Experimental hypothyroidism in dynamics, in general characterized by increased concentrations of parameters, which characterize the intensity of protein degradation and detoxification function of liver.

- From the studied in experimental hypothyroidism parameters the most pronounced differences observed among subgroups with $\alpha$ - and $\beta$ acetylation phenotypes were in the levels of creatinine.
- It is characteristic for animals with $\beta$-acetylation phenotype to have more marked changes in the values of creatinine and urea at ultimate terms of studied experimental hypothyroidism, than for animals with $\alpha$-acetylation phenotype.

\section{ACKNOWLEDGEMENTS}

Authors would like to thank junior scientific researcher Bekhzod Abdullaev for excellent technical and mental assistance. Tashkent Pharmaceutical Institute; Hematology and Blood Transfusion Scientific-Research Institute supported this study.

\section{Funding: No funding sources}

Conflict of interest: None declared

Ethical approval: The study was approved by the Institutional Ethics Committee

\section{REFERENCES}

1. Goldenkova-Pavlova IV, Bruskin SA, Abdeev RM. Comparative analysis of the results of phenol typing and genotyping for the polymorphism of $\mathrm{N}$ acetylation in humans. Genetics: Journal of Russian Academy of Sciences. 2006;42;8:1143-50.

2. Masalova NN, Zakharenko RV. State of calciumphosphorus metabolism and bone metabolism in norm and at infringement of function of a thyroid gland. Eastern Medical Journal. 2009;2:122-5.

3. Orlova MM, Rodionova TI. Biochemical and immunological markers of dysfunction in hypothyroidism. Sibir Medical Journal - Saratov, 2011;26;4:20-3.

4. Poputnikov DM, Melenchuk EV, Vismont FI. Violations of water-electrolyte metabolism (pathophysiological aspects). Textbook Minsk, BSMU; 2011:38s.

5. Shantis AK, Romashchenko SV, Yapparov IA. Correction of experimental hypothyroidism new iodine-containing drug. The achievements of science and technology APC. 2012;7:72-5.

6. Manyuk ES, Izatullin VG, Vasilieva LS. Correction of experimental hypothyroidism with herbal preparation "Bayakon". Bulletin of AUSC RAMS. 2008;59:54-7.

7. Tkachuk A. Clinical Biochemistry. ed. pers. corr. Russian Academy of Sciences, Academician of RAMS VA Tkachuk. - $2^{\text {nd }}$ ed., Revised and edited. M.: GEOTAR-MED; 2004;512.

8. Evgenyev MI, Harmonov SY, Gismyatov RG, Shitova NS, Zykov IE. Non-invasive methods of determination of acetylation phenotype. Issues of Biololgy, Medicine and pharmacist chemistry. 2003;3:34-9.

9. Nikitina LP, Solovyov NV, Tsidendambaev PB. Biochemistry of the liver in health and disease: a learning aid for teachers and medical students, physicians, interns, clinical residents. Chita CHGMA; 2004:52. 
10. Fadeev VV. Modern concepts of the diagnosis and treatment of hypothyroidism in adults. Issues of Endocrinol. 2004;2:47-53.

11. Nikolaev AY. Biological Chemistry / AY Nikolaev. $4^{\text {th }}$ ed., Rev. and ext. M.: Medical news agency; 2004:556.
Cite this article as: Saidov S, Ahmadjonuv A,

Mavlonov A. The effect of acetylation phenotype on the dynamic changes of indices of calcium

metabolism and iron levels in liver detoxification on the background of experimental hypothyroidism. Int J Basic Clin Pharmacol 2017;6:739-45. 